\title{
The science of life and death
}

\section{A look at the development of biological weapons and the threat they carry.}

\section{Biological Weapons: From the Invention of State-Sponsored Programs to Contemporary Bioterrorism \\ by Jeanne Guillemin \\ Columbia University Press: 2004. 256 pp.

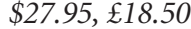

\section{Malcolm Dando}

In 2005, parties to the Biological and Toxin Weapons Convention (BTWC) will consider the "content, promulgation and adoption of codes of conduct for scientists". The United States, following a report by the National Academies, Biotechnology Research in an Age of Terrorism, has already established a National Science Advisory Board for Biosecurity, charged with increasing the controls on biological research to prevent its misuse. There is an urgent need for an informed debate among life scientists to ensure that any such controls effectively prevent misuse but interfere as little as possible with peaceful civil research and development. The problem for many life scientists is that they are not conversant with the issues surrounding biological weapons, biowarfare, bioterrorism and associated topics, despite almost a century of biology and medicine being used in offensive bioweapons programmes.

In Biological Weapons, Jeanne Guillemin aims to provide a historical context to our present concerns. Her book, she says, "is about the twentieth-century incorporation of biological weapons into the arsenals of industrial states and its implications for present times, when new technologies and persistent political animosities may allow even more ominous threats than in the past".

Guillemin divides her history into three periods: a phase covering the initial scientific understanding of infectious agents until the BTWC came into force in 1975; a second phase after the BTWC prohibited offensive bioweapons programmes, but when some nations, notably the Soviet Union, persisted illegally; and the current phase of grave concerns about bioterrorism and massive investment in biodefence.

This is a difficult story to tell straightforwardly, as Guillemin acknowledges, because much of the archival material is still unavailable to scholars, and there has been "an unusual degree of misinformation and even disinformation". The book's chapters nevertheless cover the essential elements of the story. There is discussion of the United States' weapons programme during and after the Second World War, and the US rejection of biological and toxin weapons in the run- up to the BTWC. Guillemin also covers the gruesome Japanese bioweapons programme and the use of these weapons in China. And she discusses the Soviet programme in the later years of the Cold War, including the 'yellow rain' accusations of biological weapons being used in Asia, and the accidental release of anthrax at Sverdlovsk in the Soviet Union. She also considers the lesser, and more recent, South African and Iraqi programmes, and current concerns and responses to bioterrorism threats.

Guillemin argues, quite reasonably, that a variety of restraints - notably custom and law, technological problems, a lack of military interest, government and public opinion, and fears of retaliation - have luckily prevented the widespread use of biological weapons over the past century. She also puts forward a credible argument that a wide range of integrated policies, including stronger international controls to pre-empt proliferation, will be required to prevent the future development of biological weapons. Scientists will be interested to note, however, that their fellows have been among the factors promoting the development of biological warfare in the past. In discussing potential agents, for example, Guillemin refers to a study by the eminent US scientists Theodor Rosebury and Elvin Kabat which, in 1942 , assessed the advantages and disadvantages of some 70 agents for use as weapons.
An extensive table compares this with a series of later assessments through to 2001. Again and again she stresses that scientists and others "who believed in the future of biological weapons saw their potential for fulfilling the goals of total war, that is, for the mass killing or debilitation of enemy civilians".

Chapter 2, on Britain's bioweapons programme, should be required reading for anyone who doubts this point. Particularly revealing are the views and actions of Frederick Banting, the discoverer of insulin, in support of the development of biological weapons early in the Second World War.

Before the BTWC, scientists at least had the excuse that they were doing nothing illegal in developing biological weapons, but that doesn't apply to participants in the huge Soviet programme after 1975. Guillemin devotes a chapter to this, including the illegal Biopreparat expansion, but because the evidence available today is fragmentary, there is an uneasy sense that there is much more to be discovered.

The book is largely concerned with the history of biological weapons developments, but the final three chapters are of particular interest because they discuss the implications of that history for today. How should we best assess and respond to the problem of bioweapons proliferation and the threat of bioterrorism?

For whose who believe that everything

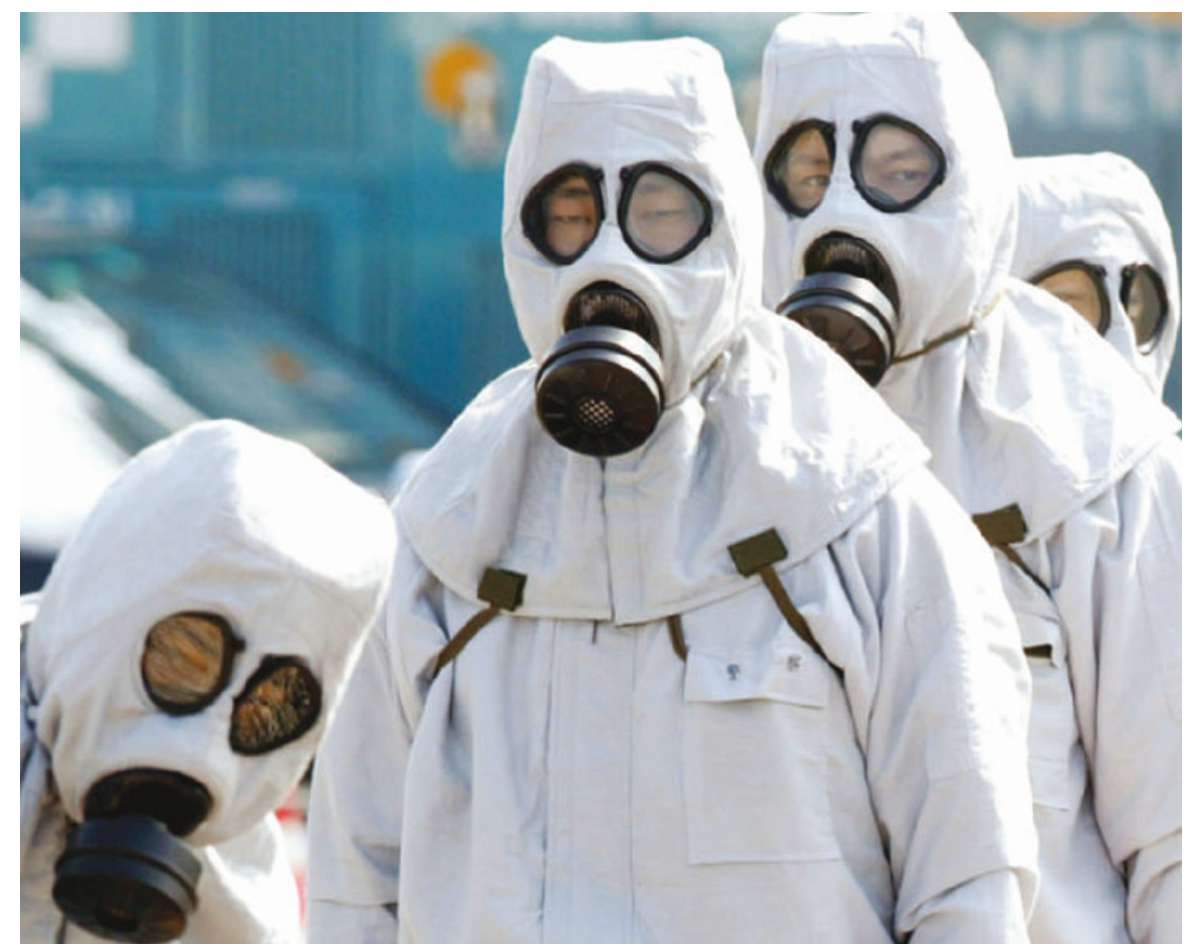

At risk: despite decades of discussion about controlling biological weapons, the threat is still with us. 
changed after the terrorist attacks of 11 September 2001, and that only then did we realize the possibility of terrorists using weapons of mass destruction, Chapter 8 will be enlightening reading. It details the escalation of high-level US concerns over this issue in the 1990s and the ever-increasing budgets allocated to deal with it. The al-Qaeda attacks and the subsequent anthrax postal attacks "intensified Clinton-era policies already in place" for national security and defence against bioweapons, says Guillemin. What did change, of course, was the scale of the budgets - including those for biodefence.

Given that the Bush administration has rejected the decade-long effort to strengthen the BTWC with a verification protocol, and that some US biodefence projects could be perceived by others as crossing the boundary between defence and offence, the vastly increased US budgets for technological solutions provoke some awkward questions. The book does not dodge them. Guillemin notes, for example, that Project Bioshield, "a biomedical equivalent of Reagan's Star Wars" defence programme, promised "universal protection from biological weapons" but was faced with the uncertainty of the threat, the technology, and the organization of national vaccinations or other campaigns. Such budgets necessarily draw more and more of the biological community into biosecurity, placing them under the restraints on openness and the free exchange of information that this work involves.

Not surprisingly, this sane and sensible book ends by arguing for a more balanced approach in which the United States joins again with its international allies to redevelop a multifaceted, integrated set of policies against the malign misuse of life sciences. Malcolm Dando is in the Department of Peace Studies, University of Bradford, Richmond Road, Bradford BD7 1DP, UK. He is co-editor, with M. L. Wheelis and L. Rozsa, of the forthcoming book Deadly Cultures: Bioweapons from 1945 to the Present (Harvard University Press).

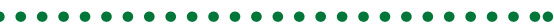 \\ The view from \\ Budapest}

\section{Our Lives: Encounters of a}

\section{Scientist}

by István Hargittai

Akadémiai Kiadó: 2004. 264 pp. €30

\section{Henryk Eisenberg}

When asked whether he believed in extraterrestrial beings, physicist Leo Szilard replied that they were already in our midst: they were called Hungarians, and he was one. The implication was that they had colonized our planet. Readers of István Hargittai's Our Lives will certainly be left with the

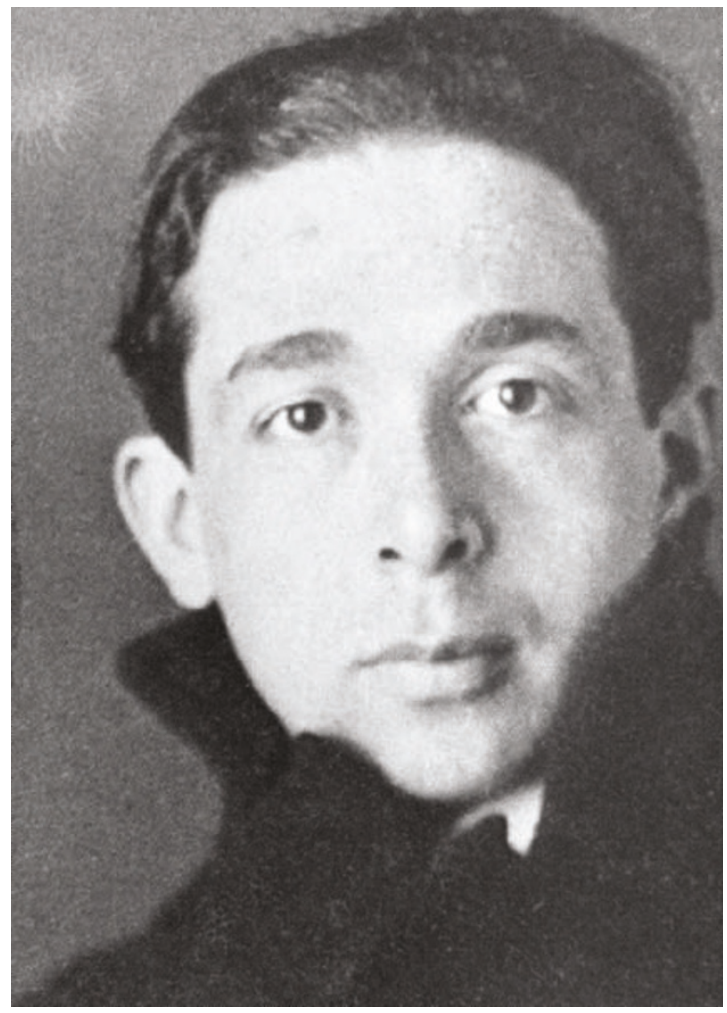

the story of his experiences at the hands of both the Nazis and their Hungarian epigones, the Arrow Cross, never previously related, is well worth the telling.

Hargittai's encounter with the chemist Gertrude Elion led him to describe another illustrious Jewish woman, the Hungarian mathematician Vera Sós, who was also persecuted, and her friend, Paul Erdös, who got away. Other Hungarian scientists whose early lives were marked by harrowing experiences were George Olah and two who settled in Sweden. One was Hargittai's friend and patron, the biochemist Lars (previously László) Ernster; the other was George Klein, the distinguished tumour biologist, who arrived fatherless in Sweden.

Roald Hoffman, the focus of another of Hargittai's chapters, was born in Poland, not Hungary, but the story of his survival as a Jewish child in occupied Europe is one of the most remarkable. Leo Szilard led the Hungarian invasion of the scientific world.

impression that they have, or the scientific world, at least.

Hargittai is a professor in Budapest who works on symmetry in chemical reactions. He has written some 25 books, many of them devoted to conversations with prominent scientists. In his latest book, Our Lives, each of the 19 chapters is centred on a Nobel laureate he has met. Interspersed with the stories of their lives and work are his own reflections and reminiscences of an eventful life spent with a wide range of friends and acquaintances. Hargittai was a child during the tragic years of the Second World War in Hungary, and his family, being Jewish, suffered persecution and endured life in a ghetto and a labour camp. His father was conscripted and was killed on the Russian front. From these circumstances arises one of the themes that permeate the book: several of his chosen Nobel laureates also never knew their fathers, or lost them in early childhood. This, Hargittai believes, may have been a formative factor in their lives.

Another recurring theme of the book is the experiences of Hungarian Jews during the war and in its aftermath. Hargittai and his mother were saved from deportation to Auschwitz by a deal that rescued many Hungarian Jews at the eleventh hour. They were given shelter until Hungary's leader, Miklós Horthy, belatedly changed sides. Hargittai's brother and other members of the family were less fortunate, and their sufferings are movingly described. One of Hargittai's Jewish friends who was deported to Auschwitz and survived was the chemist László Kiss;
He made his way to the United States with no money and after a late start emerged as one of the outstanding chemists of our times.

Many remarkable characters flit through these pages. Hargittai finds the human side of another Hungarian Jew, the abrasive and much disparaged Edward Teller, and discusses the political influence of Arthur Koestler. Hargittai has interesting things to say on science in the Soviet Union, which he experienced at first hand as a graduate student in Moscow, where he became acquainted with several distinguished chemists. He recounts the remarkable episode of the denunciation on ideological grounds of Linus Pauling's theory of resonance. He also seeks to right the injustice done to his compatriot Árpád Furka, who received too little credit for his central contribution to the conception of combinatorial chemistry. In 1967, Hargittai married the chemist Magdolna Vámhidy, who became his co-author on several books.

Many more scientists appear in Our Lives. Hargittai's aim is to blend the achievements of modern science with his own life in this turbulent period, taking in his family, the special place of Jewish and Hungarian scientists and thinkers in twentieth-century history, anti-Semitism and the terror of Nazi persecution. This is not an easy task in such a short book, and the components are sometimes difficult to disentangle. But the stories he tells have a great deal to offer to anyone interested in the broader aspects of science in our time.

Henryk Eisenberg is in the Department of Structural Biology, Weizmann Institute of Science, Rehovot 76100, Israel. 